\title{
The ISOTILT program for discovering cooperative rigid-unit modes (RUMs) in crystalline solids
}

\author{
B Campbell ${ }^{1}$, H Stokes ${ }^{2}$, S Machlus ${ }^{3}$, C Yost $^{2}$ \\ ${ }^{1}$ Brigham Young University, Springville, UT, ${ }^{2}$ Brigham Young University, Provo, UT, ${ }^{3}$ Brigham \\ Young U., Florida State U., Provo, UT \\ branton.campbell@gmail.com
}

Structural phase transitions in crystalline materials with networks of interconnected rigid units require that any rigid-unit modes (RUMs) be largely cooperative in nature to avoid distorting the rigid units or pulling them apart. For three-dimensional networks, cooperation can be a rather severe constraint, so that RUMs can be difficult to identify when they exist at all. A new approach to discovering RUMs was recently reported [1], in which linearizing the network constraints in the limit of small rotations transformed a non-linear trigonometric problem into a homogeneous linear system of equations. We now report a series of theoretical advances that has made it possible to identify RUMs quickly and accurately, even in very large and complicated systems. The original method, enhanced by these advances, has now been implemented as a new web-based software program called ISOTILT, and included as part of the ISOTROPY Software Suite. [2] [1] B. J. Campbell, C. J. Howard, T. B. Averett, T. A. Whittle, S. Schmid, S. Machlus, C. Yost, H. T. Stokes, Acta Cryst. A 74, 408-424 (2018). [2] H. T. Stokes, D. M. Hatch, B. J. Campbell, ISOTROPY Software Suite, iso.byu.edu. 